\title{
Metodologias ativas numa escola técnica profissionalizante
}

\section{RESUMO}

A quarta revolução industrial tem crescido exponencialmente e visualiza-se através da manufatura aditiva (impressões 3D e 4D), big data, Internet das Coisas - IoT (Internet of Things), sensores inteligentes, realidade aumentada, digitalização, inteligência artificial, robótica colaborativa, dentre outros avanços na chamada Indústria 4.0. Assim, o objetivo deste trabalho foi investigar como a metodologia da Educação 4.0 pode apoiar as estratégias pedagógicas numa escola técnica, oferecendo novos recursos de ensino e prática para formar profissionais para esse advento. Foi realizado um estudo de caso descritivo, de natureza qualitativa, através da implementação de uma metodologia baseada nos fundamentos da Educação 4.0 num curso de mecatrónica numa escola técnica, na disciplina de Robótica, recorrendo à observação participante para descrever os efeitos do novo formato de aplicação das aulas. A Educação 4.0, com as suas metodologias ativas, demonstrou que o aluno participante nessas aulas foi capaz de compreender, identificar, aperfeiçoar e agir dentro da quarta revolução industrial, obtendo as competências necessárias que esse mercado exige. A mudança parece ser inevitável com a Indústria 4.0, inclusive dentro do ambiente educacional, fazendo da Educação 4.0 a palavra de ordem entre os educadores que queiram preparar profissionais eficazes para o mercado de trabalho.

Palavras-chave: Robótica, Educação 4.0, Indústria 4.0, Metodologias Ativas.

\section{INTRODUÇÃO}

Atualmente, o mundo passa por um processo de avanços tecnológicos de forma exponencial. Essa modernização é conhecida pelos especialistas da área, que já identificam diferentes nomes, como Indústria 4.0 (I4 ou I4.0), manufatura avançada ou quarta revolução industrial, porém todos estes nomes apontam no sentido de um marcante conjunto de alterações nos processos de manufatura, design, produto, operações e sistemas relacionados à produção.

Esse termo foi cunhado por meio de um trabalho do governo Alemão, pensando no futuro trajeto da manufatura das empresas, onde é possível,
Ederson Carlos Silva ${ }^{i}$ ETEC Pedro Ferreira Alves, São Paulo, Brasil

Helena Brandão Viana ${ }^{\text {ii }}$ UNASP - Centro Universitário Adventista Engenheiro Coelho, São Paulo, Brasil

Guanis de Barros Vilela Jr.iii

Universidade Metodista de Piracicaba, São Paulo Brasil 
através das novas tecnologias habilitadoras, generalizar a automação da produção, reduzir os custos, aumentar a eficiência fabril e incrementar a qualidade. Trata-se de uma integração, em que o mundo virtual se funde ao físico e juntos operam proporcionando uma cadeia de valores altamente integrada, permitindo sua inserção às redes globais (Prause \& Wergand, 2016).

No Brasil, a nova era industrial tecnológica tem clamado pela atenção dos empresários, porém, no consenso de especialistas de fóruns económicos, a indústria nacional encontra-se num patamar abaixo da indústria mundial. As indústrias nacionais estão agora aderindo à terceira revolução industrial, onde se faz o uso da automação através da eletrónica, robótica, programação e redes.

Em cada revolução industrial surgiu uma tecnologia específica diferenciada e destacada, e com esses adventos veio a necessidade de um profissional modificado frente às novas tecnologias emergentes, alterando assim o perfil desejado. Houve também a necessidade de capacitar os indivíduos de forma eficaz, proporcionando de maneira rápida a formação especializada de pessoas para atuar nas organizações.

Trabalhando em parceria com as organizações, as instituições de ensino têm por obrigatoriedade desvendar a necessidade das empresas nessa nova tendência, adaptando o profissional e preparando-o para as complexidades das novas tecnologias, como a robótica, que está em alta nas corporações (Aires et al., 2017; Coutinho, 2008).

A robótica está presente nos cursos de ensino técnico de mecatrónica e automação industrial das escolas técnicas do estado de São Paulo. O plano pedagógico dessa disciplina está inserido na aplicação industrial, onde o aluno, após a sua formação, é o profissional que atua no projeto, na execução e na instalação de máquinas e equipamentos automatizados e sistemas robotizados, realizando igualmente manutenção, medições e testes dessas máquinas, equipamentos e sistemas, utiliza Software específicos e linguagens de programação adequadas (Centro Estadual de Educação Tecnológica Paula Souza, 2009).

0 grande desafio é deixar o aluno preparado para um mercado futuro com realidade multicultural, onde ele deverá desenvolver as habilidades de forma multidisciplinar - preparando as suas ideologias para a prática de um pensamento complexo e inclusivo - como também inovar a sua contextualização com o intuito de aplicar as suas teorias às necessidades e desafios que a Indústria 4.0 está impondo (Kloc et al., 2009).

Com uma metodologia diferenciada, baseada na criatividade, no construtivismo e no conectivismo, o aluno poderá construir, por meio da sua motivação em visualizar resultados, a sua própria aprendizagem através de pesquisas científicas e tecnológicas, bem como através da troca de experiências, uma vez que também estão inclusos nesta metodologia o trabalho em grupo e o desenvolvimento final em equipa.

A aplicação das atividades de robótica constrói-se através das teorias e atividades colocadas por Piaget (1996), onde o construtivismo é a raiz para o desenvolvimento do ensino e aprendizagem.

Para Piaget, aplicar os conhecimentos formais aos problemas reais é o principal objetivo na educação desenvolvendo assim alunos capazes de 
criar, inovar e descobrir. Também cria na educação, mentes que não aceitam tudo que lhes é imposto, tudo que é oferecido, resultando em indivíduos críticos e formadores de opinião. Criar e construir o seu universo de conhecimento é a tendência construtivista. Através da prática laboratorial com tecnologia, o aluno busca criar desafios para seu projeto, exigindo do seu intelecto a construção do seu próprio conhecimento (Kloc et al., 2009).

Também fomenta a necessidade de aprendizagem corporativa sugerido por Aires, Moreira e Freire (2017), que exalta, com essa intenção de aprender, a criatividade, a inovação, a solução de problemas e o conhecimento técnico, quatro das cinco competências relacionadas mais requeridas para o futuro profissional frente à quarta revolução industrial. Espera-se igualmente a aplicação sugerida por Siemens (2004), sobre o conectivismo, processo progressista do construtivismo.

\section{METODOLOGIAS ATIVAS NA EDUCAÇÃO 4.0}

0 advento da Indústria 4.0, a globalização e o avanço tecnológico exigem modificações nos sistemas industriais, modelos de negócio e simultaneamente na educação. Caminhos diferenciados devem ser construídos para que os alunos se tornem críticos e mais atuantes. Como vencer esse desafio?

Diante do cenário da Educação 4.0 (E4), a principal característica é o fato das tecnologias estarem cada vez mais presentes no nosso cotidiano e na sala de aula, promovendo e estimulando a troca de conhecimento.

Porém, o foco deixa de ser os recursos tecnológicos e passa a ser a forma de utilizar essas ferramentas digitais, e como elas podem proporcionar interação, ludicidade e o fazer coletivo. A tecnologia por si só não é capaz de elevar o conhecimento do aluno; é preciso uma metodologia educativa, como a E4, que foi aplicada nesta pesquisa. Portanto, uma metodologia ativa deve ter cunho específico de aplicação e deve ser definida que metodologia será aplicada, visando facilitar o processo de aprendizagem, a compreensão do conteúdo proposto e o desenvolvimento das competências definida pelo plano pedagógico (Silva \& Andrade, 2019).

No entanto, não basta aplicar as metodologias ativas: é imperativo que haja um processo de planeamento, uma vez que, ao iniciar, o educador está realizando uma mudança de cultura dentro da sala de aula, onde alunos irão ficar recetivos e outros incomodados. É comum que o planeamento ocorra paralelo ao plano de curso, com integração se possível dos outros componentes curriculares.

0 termo "metodologias ativas" tem-se destacado nos últimos anos no ensino, de maneira geral, e segundo Andrade (2019) é necessário aplicar tais metodologias em sala de aula para melhorar a aprendizagem. Os benefícios dessas metodologias, segundo Andrade (2019, p. 9), são: autonomia para os alunos; construção do conhecimento; conexão e interação entre os alunos e professores; pensamento crítico; criatividade; engajamento dos alunos; melhor aproveitamento das aulas; democratização da educação. 
Então, para cada qualidade que o professor busca identificar no aluno, temos metodologias que melhor desenvolvem essas qualidades, como cita Morán (2015):

As metodologias precisam acompanhar os objetivos pretendidos. Se queremos que os alunos sejam proativos, precisamos adotar metodologias em que os alunos se envolvam em atividades cada vez mais complexas, em que tenham que tomar decisões e avaliar os resultados, com apoio de materiais relevantes. Se queremos que sejam criativos, eles precisam experimentar inúmeras novas possibilidades de mostrar sua iniciativa. (Morán, 2015, p. 17)

As metodologias ativas mais aplicadas atualmente, através da E4, são:

- Ensino Híbrido - integra o ensino online e offline e as tarefas feitas em casa no formato à distância, grupos de debates, etc.;

- Aprendizagem Baseada em Projetos ou Problemas (conhecida por PBL) - trabalha o ensino com projetos ou problemas; a solução do problema ou desenvolvimento do projeto permite um ensino diferenciado;

- Sala de Aula Invertida ou Flipped Classroom (FC) - o conteúdo é estudado em casa e, na escola, todos esclarecem dúvidas e compartilham o aprendizado;

- STEAM - Termo em inglês para o uso multidisciplinar de Ciências, Tecnologia, Engenharia, Arte e Matemática; e

- Cultura Maker - Ênfase na cultura do aprender fazendo e na aprendizagem criativa e inovadora.

\section{MÉTODOS}

Neste estudo, foi realizado um trabalho específico com os fundamentos da Educação 4.0 na disciplina de Robótica e Manufatura Flexível, que está inserida no último período letivo do curso de Ensino Técnico Integrado ao Médio (ETIM) da Escola Técnica Estadual localizada na cidade de Mogi Mirim, e que é uma das duzentas e vinte e três escolas técnicas do Centro Paula Souza, autarquia vinculada à Secretaria do Desenvolvimento Econômico, Ciência e Tecnologia do governo do estado de São Paulo.

Entre outros cursos que a escola oferece, o curso de mecatrónica tem duração de três anos e os alunos da ETEC, no seu último ano, começam a cursar a disciplina de robótica. A turma do terceiro ano foi selecionada para a realização da pesquisa devido aos conhecimentos imprescindíveis para o aprendizado de robótica, obtidos nas disciplinas já cursadas nos dois anos anteriores, como mecânica (pneumática, hidráulica e cinemática), eletrónica (sensores e atuadores), elétrica (comandos elétricos, motores e servos), software e programação (microcontroladores e controladores lógicos programáveis - CLP). 
Esta pesquisa foi aprovada pelo comité de ética do UNASP, sob número CAAE, 91699218.3 .0000 .5377 e parecer 066984 , em 2018. Os pais dos alunos menores de idade participantes na pesquisa e os alunos maiores de idade assinaram o Termo de Consentimento Livre e Esclarecido (TCLE).

\section{IMPLEMENTAÇÃO DA EDUCAÇÃO 4.0}

Com a necessidade de alterar a metodologia em sala de aula conciliando os conceitos de Educação 4.0 para a matéria de robótica, foi realizada uma modificação no plano de aula, identificando a necessidade da indústria atual, e consequentemente buscando valorizar o construtivismo e conectivismo do aluno.

Conceitos de Indústria 4.0 foram implementados nas aulas de robótica, com o aluno trabalhando de maneira teórica e prática, tanto o conhecimento tradicional da disciplina que é fundamental para chegarmos à Educação 4.0, como o conhecimento que promove a sua inserção no mercado de manufatura avançada.

Sendo assim, para o desenvolvimento da aplicação da E4 para a disciplina de robótica, foram utilizadas as metodologias ativas PBL, ensino híbrido, FC, STEAM e Cultura Maker. Para essas transformações acontecerem, foi necessário a união dos professores e gestores da comunidade escolar, principalmente o apoio das famílias e dos protagonistas, os alunos. Na Figura 1, apresenta-se um fluxograma que identifica essa transformação e podemos visualizar os três pilares da educação 4.0.

\section{Figura 1}

Fluxograma de integração para uma boa atividade escolar prática

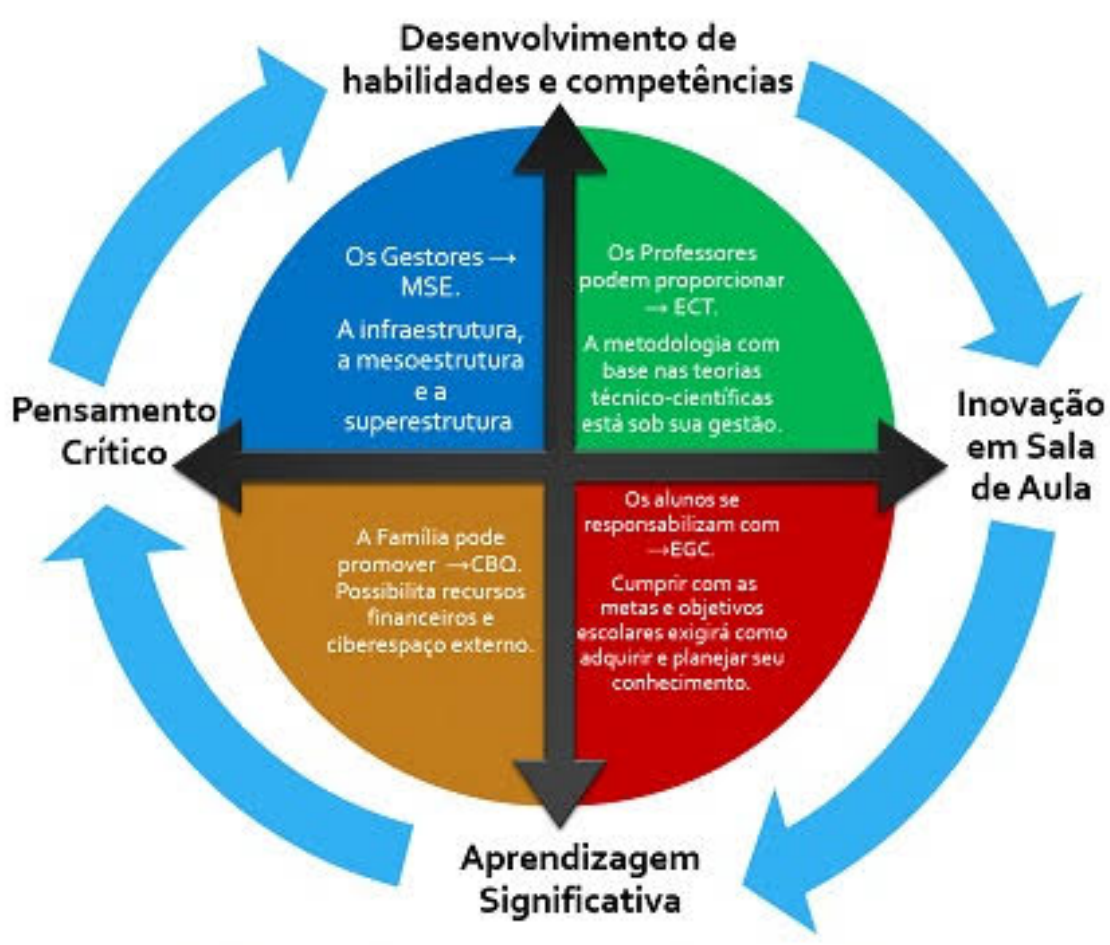

Fonte: Próprio autor. 
Na Figura 1, observa-se que:

- O MSE (Modelo sistémico de educação) está totalmente relacionado aos Gestores (azul), ficando sob responsabilidade destes a infraestrutura, a mesoestrutura e a superestrutura;

- Os Professores (verde), podem proporcionar a ECT (Educação Científica e Tecnológica), uma vez que a metodologia com base nas teorias técnico-científicas está sob sua gestão;

- Com a EGC (Engenharia e Gestão do Conhecimento), os Alunos (vermelho) responsabilizam-se por cumprir com as suas metas e objetivos, pois a necessidade da participação em sala de aula exigirá como adquirir e planear seu conhecimento;

- A Família (laranja) pode promover CBQ (Ciberarquitetura), possibilitando recursos financeiros para criação de ambientes tecnológicos, ciberespaço além dos do cotidiano escolar.

Portanto, toda essa parceria permitiu a integração do conteúdo curricular às tecnologias, para fazer com que o planeamento das aulas pudesse explorar as suas possibilidades e utilizar metodologias ativas que potenciam o trabalho com projetos, investigação, resolução de problemas e produções de narrativas por meio dos recursos digitais disponíveis na escola e, se possível, fora da escola também.

Colocando em prática, um ambiente inovador foi necessário (ciberarquitetura). Os ambientes que foram utilizados permitiram o desenvolvimento prático do efetivo trabalho solicitado, e essa criação de ambiente foi destaque para as iniciativas de um polo de inovação dentro do ambiente escolar (Figura 2).

\section{Figura 2}

Sala de processos de manufatura: Uma sala altamente tecnológica, computadorizada e equipada

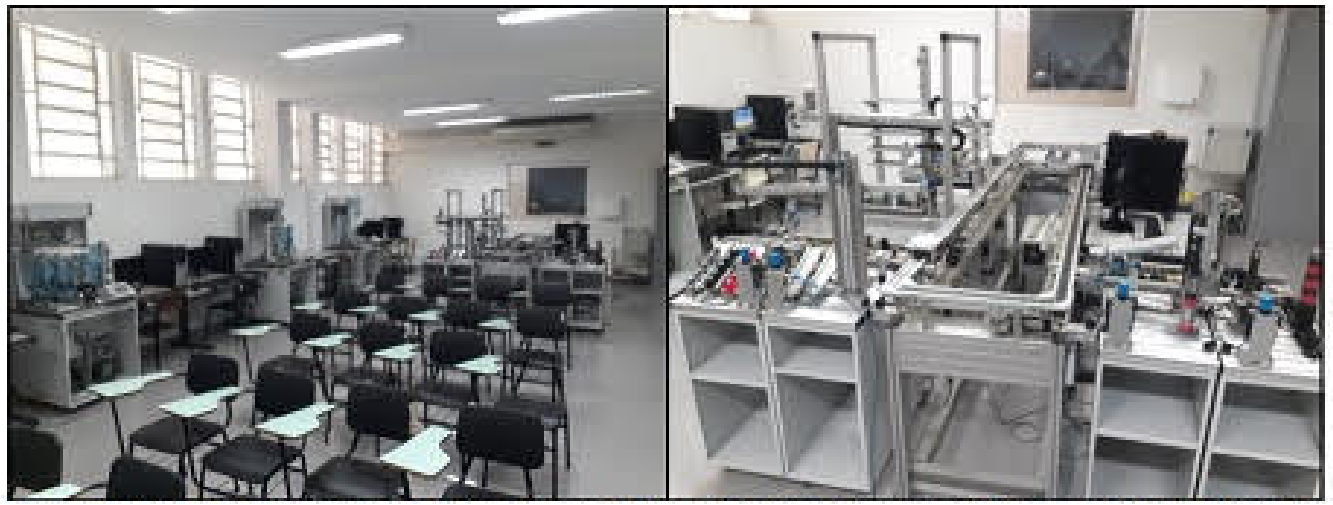

Fonte: Próprio autor.

A principal mudança realizada nessa disciplina foi a diminuição das aulas teóricas expositivas e o aumento das aulas práticas laboratoriais, e a maior parte do conteúdo aprendido vinha de uma experiência prática que simulava com maior perfeição o cotidiano empresarial.

Na didática, foi necessário aplicar a metodologia de aula invertida para que os alunos viessem com um pouco do conteúdo lido em casa e na aula 
tirassem dúvidas. Isso permitiu que uma grande parte do tempo que seria utilizado para ensinar a teoria em aulas expositivas fosse aproveitado para as atividades práticas interativas.

A sala de eletrónica e o LabTec (Laboratório da ETEC, atualmente conhecido no mundo como FabLab - laboratório de fabricação) foram utilizados para desenvolvimento de protótipos para elaboração de projetos mais avançados. Nesses protótipos, os alunos desenvolveram robôs de batalha.

Depois da construção mecânica, os alunos elaboraram um projeto utilizando tecnologia Arduino, ensinado nas aulas de microcontroladores, como aprendizagem adicional ao plano de trabalho docente proposto (mudança do plano de aula docente) para elaborar as partes elétricas e eletrónicas de cada robô.

$\mathrm{Na}$ disciplina de microcontroladores, todos os alunos, através de equipas, montaram projetos que visavam a comunicação de dados e execução de trabalhos voltados para aplicação da mecatrónica em todos os ambientes de trabalho.

Nesse ambiente de criação de projetos de robôs, inovação e criatividade foram exigidas. Todos os robôs necessitavam atingir um objetivo complexo, que era serem capazes de agredir e defender-se de um robô adversário, e por isso precisaram de ser projetados com a máxima atenção (Figura 3).

Essa demanda possibilitou aos alunos a procura de soluções inteligentes e diferenciadas por conta própria, através de um pensamento crítico, permitindo estimular a criatividade e trabalhar em conjunto com a inovação.

\section{Figura 3}

Modelos de robôs de batalha utilizando comunicação de dados entre controle e sistema de processamento de informação através da placa Arduino

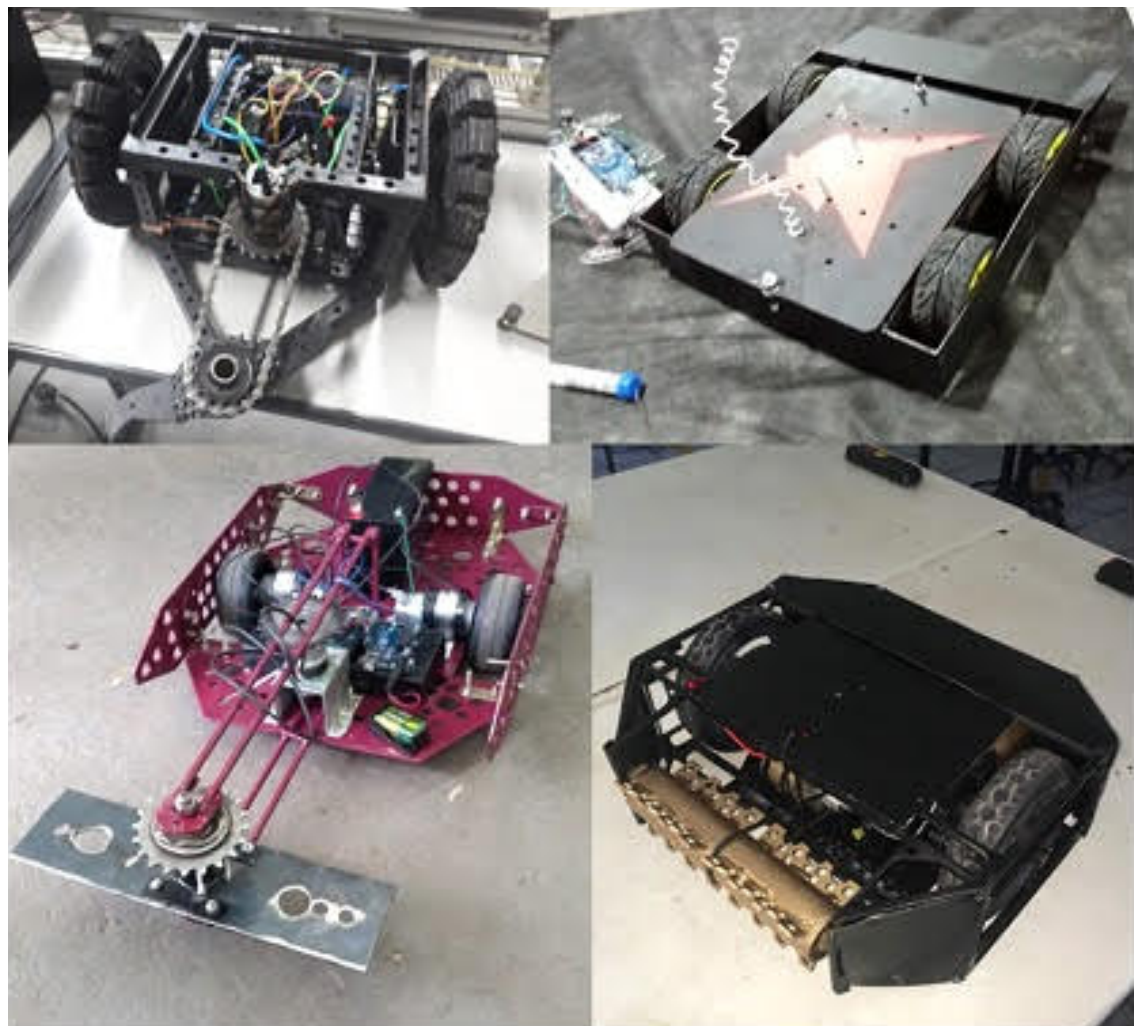

Fonte: Próprio autor. 
Na sala de robótica, os desenvolvimentos ocorreram nos processos de programação, implementação de acionamentos de máquinas e de equipamentos. Essa sala é equipada com robôs manipuladores ABB, KUKA e um modelo AGV Robotino, equipamentos idênticos aos usados pelas corporações. Na temática das aulas de robótica, quando propostos exercícios de resolução de problemas através de programação com sensoriamento utilizando esteira rolante e robô, ocorreram soluções imediatas por parte dos alunos, testes de sistemas de produção e sistemas de automação em manufatura flexível que permitiram uma aprendizagem significativa.

Essa aprendizagem foi possível, porque os trabalhos práticos foram realizados com materiais reais, que estão sendo utilizados também pelas empresas. Nesta situação o aluno também foi capaz de vislumbrar uma aplicação industrial real.

Nas aulas de robótica, os alunos atuaram em equipa, seguindo normas, e novamente agindo com iniciativa e muita empatia, pois os seus trabalhos foram apresentados para alunos de outros cursos da própria escola. A aprendizagem significativa permitiu o conhecimento através de atividades práticas sugeridas pelo professor.

A mudança didática nessa parte foi enorme, pois excluiu-se o uso de apresentações expositivas com Datashow nas aulas. Partiu-se do pressuposto que todas as aulas deveriam ser práticas, mesmo a escola possuindo apenas dois braços manipuladores. A turma pesquisada possuía 37 alunos e são poucos robôs para cada aluno, portanto fez-se uso de um guia para acompanhamento do passo a passo de uso dos Programas QuickTeach da ABB, e KUKAsim (Figura 4).

\section{Figura 4}

Software QuickTeach. Permite a simulação das atividades práticas reais que acontecem com robô $A B B$

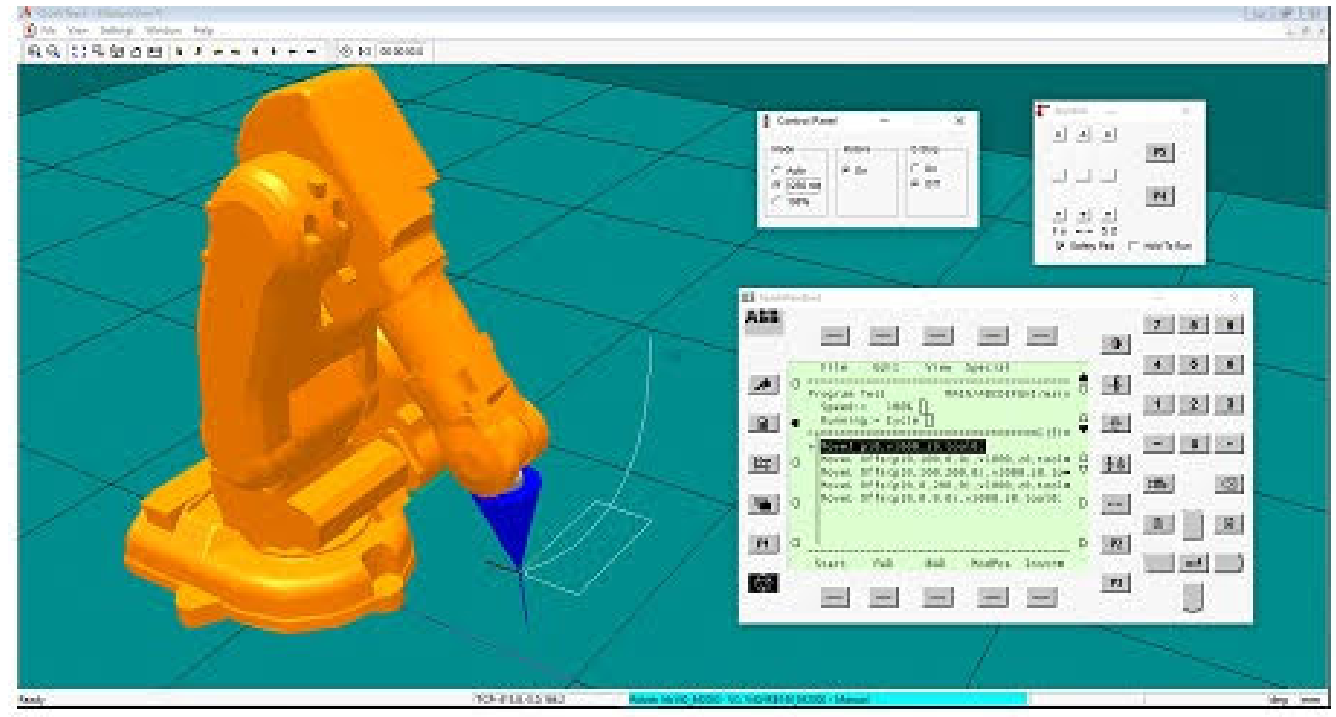

Fonte: Próprio autor.

Estes softwares possibilitaram aos alunos executarem os seus projetos, visualizando possíveis erros e corrigindo-os, assim evitando danos que seriam reais se a atividade fosse realizada diretamente no braço manipulador; 
ou seja, o aluno realizava no software uma simulação que, depois de executada corretamente, lhe era permitido que executasse no robô manipulador, de maneira real.

Desta forma, os alunos (em duplas formando equipas de trabalho) puderam realizar os seus projetos de desenho ${ }^{1}$ com os robôs (Figura 5), que é o conhecimento inicial para então aprender sobre sensoriamento na robotização (entradas e saídas digitais e analógicas), e assim concluir o seu trabalho na disciplina de robótica e manufatura flexível. Decorre que a função do professor nesta etapa é passar o conhecimento, sendo a prática e o desenvolvimento da responsabilidade dos alunos, que executam os seus projetos com criatividade, sentem-se realizados e motivados.

\section{Figura 5}

Aplicações práticas feitas pelos alunos. Depois de simularem no Software

QuickTeach essas são as execuções físicas no robô $A B B$

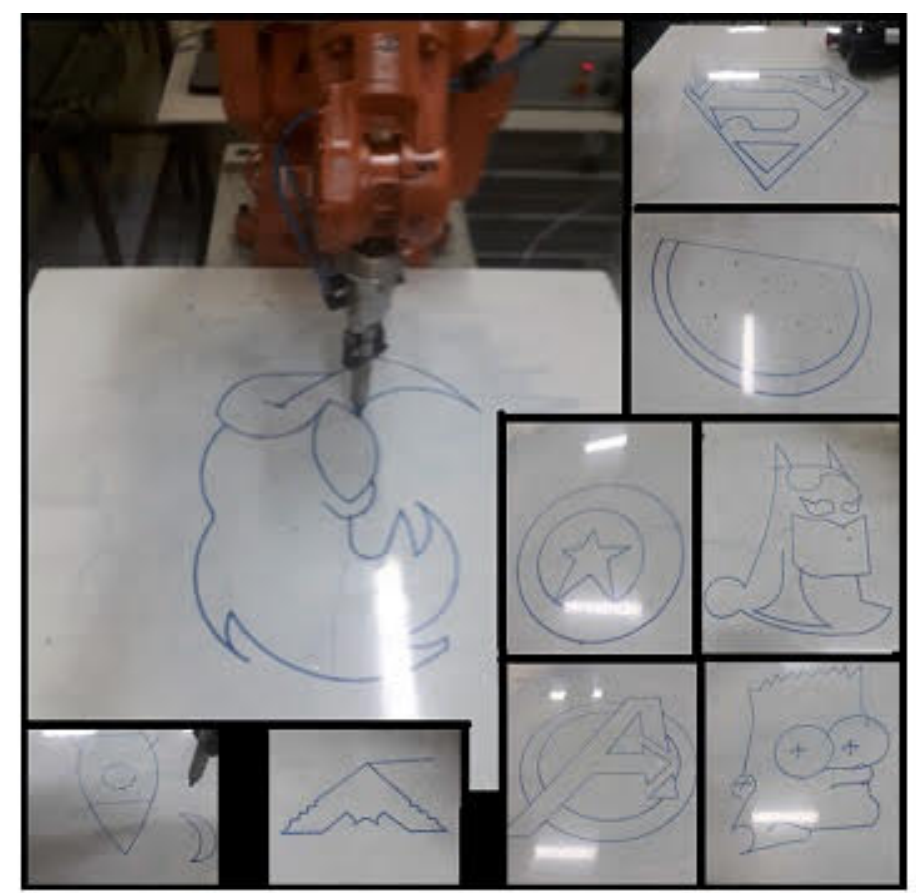

Fonte: Próprio autor.

O conceito STEAM é um dos conceitos mais aplicados na Educação 4.0 para promover o conhecimento técnico dos jovens que pretendem ingressar na carreira industrial (Andrade, 2019). O software Quick Teach e KUKAsim, utilizado nas aulas, combina conceitos de robótica, engenharia e programação, e estimula a solução de problemas. Em conjunto, todo esse processo permite tornar as apresentações dos projetos muito mais dinâmicas. Esses programas enriquecem o aluno com conhecimento específico; porém, as habilidades e competências mais próximas possíveis dos perfis profissionais de manufatura avançada que as empresas solicitam emergem da fusão entre os conceitos adquiridos em microcontroladores e robótica.

A Cultura Maker aplicada nas escolas é um fenómeno que permite aos participantes desenvolver os seus projetos na prática, por meio do conhecido conceito do "faça você mesmo" (Do It Yourself - DIY). Através desse
1. A realização de desenhos com pincel feita pelo robô é o início de uma aplicação prática da disciplina de Robótica, uma vez que, através desta, o aluno aprende sobre coordenadas cartesianas $(X, Y$ e Z) e movimentação básica do manipulador. 
processo, o incentivo a realizar algo que realmente aconteça propicia ao aluno a aquisição de habilidades durante o processo que, de outra forma, o professor não seria capaz de proporcionar.

Segundo Mark Hatch (2013), no seu livro The Maker Movement Manifesto, os mandamentos para uma pessoa se tornar um maker são: faça; compartilhe; doe; aprenda; equipe-se; brinque; participe; apoie; modifique. São esses os códigos de conduta que promovem um bom maker. Hatch (2013) ainda menciona que o incentivo à colaboração é outro ponto importante, seja através da partilha de informações ou da combinação das habilidades individuais dos membros de uma equipe em prol de um objetivo comum.

Os materiais de eletrónica e a placa de desenvolvimento Arduino são hoje o ápice da cultura maker. Trabalhando estes conceitos, o aluno consegue inicialmente automatizar uma residência e controlar lâmpadas, portões, tomadas elétricas e outros. Se, num estádio inicial, tal permite criar a domótica, com conhecimento avançado, laboratórios que auxiliam e professores que encorajam, o aluno será capaz de automatizar uma empresa ou até permitir a introdução de uma manufatura avançada, construindo desta forma o conceito e aplicação da E4.0.

A metodologia ativa FC, ou sala de aula invertida, vem para ressarcir o tempo utilizado em sala de aula para ensinar a teoria propriamente escrita. Muito utilizado por professores de instituições de ensino superior e de cursos técnicos, ela visa valorizar o tempo do aluno em sala de aula, sendo a prioridade para o professor colocar foco na aprendizagem do aluno, deixando de lado o ensino de novos conteúdos (Piva Jr \& Cortelazo, 2019).

A sala de aula invertida salienta que o aluno deve realizar a tarefa de estudar a teoria num ambiente diferente da escola, inicialmente indicado pelo professor. Depois desse estudo, em sala de aula (presencialmente) as dúvidas e os exercícios de aplicação ou atividades práticas são desenvolvidos em conjunto com o professor.

Para a realização dessa metodologia, foi utilizado o site do próprio investigador para a disponibilização de conteúdo da disciplina de microcontroladores. Sendo assim, os alunos buscavam a teoria no site, estudavam, e traziam para a sala de aula as dúvidas, que eram seguidas das atividades práticas de montagem dessas teorias. Para esse exemplo, foi utilizado o Arduino.

Essa atividade, realizada como prática de metodologias ativas, potenciou uma melhoria no desenvolvimento das atividades pedagógicas da escola, uma nova aprendizagem para o professor que aplica as novas metodologias ativas, uma nova postura dos alunos e a participação ativa de todos os estudantes envolvidos.

\section{RESULTADOS E DISCUSSÃO}

A incorporação das ferramentas tecnológicas provocou mudanças efetivas na forma de como se constitui a dinâmica do ensino. As Tecnologias Digitais da Informação e Comunicação (TDIC) contêm recursos didático-pedagógicos que podem ser utilizados no contexto educacional, possibilitando aos alunos e educadores a apropriação de habilidades e competências de forma interativa. 
Um diário de campo foi utilizado para anotações das habilidades que cada aluno conseguia atingir. Mais do que as habilidades, também foi anotado todo o desenvolvimento de aprendizagem do aluno, questões físicas, emocionais e sociais. Esses dados, anotados num diário de campo, possibilitam a compreensão e interpretação, e contribuem para a análise e processo de investigação nos estudos qualitativos (Ensslin \& Vianna, 2008).

Como o diário de campo é um dos instrumentos mais básicos de anotação de dados para um investigador, todas as anotações de cunho analítico foram inseridas num documento em formato Excel, que continha o nome de todos os 37 alunos da sala pesquisada, as habilidades e competências necessárias para o profissional requisitado para a indústria 4.0, os demais dados com características pessoais dos alunos e as qualidades desenvolvidas em grupo.

No diário de campo pode-se notar, pelas experiências vividas pelos alunos, que houve muito desenvolvimento pessoal. Características pessoais que somente o tempo pode trazer, como a maturidade, foram antecipadas.

0 grupo também desenvolveu um trabalho em equipa de qualidade. Como observador-investigador, foi possível perceber que uma grande maioria de alunos da sala tinha a preocupação de como seria a sua apresentação e participação final do projeto de Trabalho de Conclusão de Curso, que, conforme mencionado, era um robô de batalha. Nesse contexto, tratava-se da EXPOETE, um evento onde os alunos apresentaram o seu trabalho para toda a escola, e depois realizaram a batalha de robôs. Os componentes de observação nessa atividade foram:

- Apresentação - Os alunos deveriam fazer uma apresentação de qualidade ao público, não apenas com slides com design bem elaborado, mas sendo igualmente cuidadosos na interação com o público. Os comportamentos na apresentação também superaram as expectativas, uma vez que os principais apresentadores dos projetos interagiram com o público de forma a envolvê-lo na apresentação;

- Técnica - De maneira análoga, os alunos necessitam do conhecimento técnico para expor os seus trabalhos. Esse conhecimento adquirido tornou-os confiantes e desembaraçados nas suas apresentações. Percebeu-se, então, que aqueles que assumiam a frente da exposição dos seus projetos ao público tornaram-se comunicadores eficientes e seguros.

Sendo assim, seguindo os pressupostos da ECT (como a teoria da atividade de Leontiev (1978) e a teoria sociocultural da media de Thompson (2011), conseguiu-se alcançar variáveis determinantes para realizar o objetivo desse trabalho, como as características de comunicação e conhecimento técnico, duas das cinco competências propostas por Aires et al. (2017) para o desenvolvimento de um profissional para a indústria 4.0.

Através das teorias da EGC, com o conhecimento tácito desenvolvido, os estudantes souberam aplicar as suas pesquisas de campo para adquirir conhecimento e habilidades específicas para aplicação. No campo de observação, o conhecimento explícito dos alunos (como seguir regras, adquirir informações e dados) foi excluído na maior parte das vezes do seu plano de utilização cotidiana; ou seja, só a informação, sem aplicação, era descartada. 
Uma característica importante para a utilização de media, em virtude de melhorar o conhecimento tácito (desenvolver habilidades e competências, e saber aplicar tais desenvolvimento), foi possível devido ao incentivo da CBQ que possibilita um ambiente didático diferenciado, com utilização de tecnologias auxiliadoras e materiais de estudo disponíveis em todo os lugares e horários.

O postulado de Siemens (2004), teoria da conectividade - que integra os pressupostos teóricos de Leontiev (1978) e Vygotsky (1989) através da teoria da atividade e da teoria sócio-histórica - foi observado através das práticas metodológicas ativas, onde a sala de aula invertida e a cultura maker potenciaram uma melhor formação do aluno, tornando-o criativo, inovador e descobridor. Ressaltamos aqui, que criatividade e inovação são duas das cinco competências que Aires et al. (2017) afirmam serem necessárias para o profissional da indústria 4.0. 0 conectivismo de Siemens (2004) foi aplicado nas aulas de microcontroladores, onde o estudante integrava a ciberarquitetura com a sala de aula invertida, pois necessitava procurar antecipadamente a matéria da disciplina e fazia uso dos ambientes de aprendizagem em ambiente diferenciado (CBQ).

Percebeu-se também o desenvolvimento da autonomia nos alunos à medida que pesquisavam em fontes diversas através da metodologia STEAM e PBL, bem como o interesse em procurar respostas aos questionamentos, sem a solicitação do professor.

A observação participante direta desses alunos foi prolongada e frequente durante todo o processo de aprendizagem daquele ano, paralelamente trabalhado com o plano pedagógico, conseguindo-se perceber fatores sociais em que alunos de diferentes contextos culturais perceberam que não há limites para o seu desenvolvimento, autonomia, democratização, etc.

Tal observação, sendo participante, tornou o observador outro instrumento de pesquisa a ser avaliado, transformando igualmente esse investigador num educador com capacidade e habilidade para aplicar as técnicas da Educação 4.0 de forma mais eficiente.

\section{CONSIDERAÇÕES FINAIS}

Este trabalho propôs-se investigar a metodologia da Educação 4.0, trabalhando em paralelo com as tecnologias habilitadoras da quarta revolução industrial, para então conseguir atingir o objetivo de apoiar as estratégias pedagógicas numa escola técnica, principalmente em disciplinas de robótica, proporcionando novos recursos de ensino para formar profissionais para esse advento.

O objetivo da escola técnica é formar profissionais; contudo, com a aplicação dos pilares da Educação 4.0 (como o Modelo Sistémico de Educação, a Educação Científica e Tecnológica, a Engenharia e Gestão do Conhecimento, e a Ciberarquitetura) conseguiremos formar profissionais eficientes e qualificados, com as características e competências que a Indústria 4.0 requer.

Essas competências foram desenvolvidas durante um ano letivo, podendo o aluno demonstrar a sua capacidade de ser criativo, inovador, 
solucionador de problemas, comunicativo e ter conhecimento técnico na área. Esta nova metodologia demonstrou que o aluno participante nestas aulas foi capaz de compreender, identificar, aperfeiçoar e agir dentro da quarta revolução industrial.

Durante todo este ano letivo, realizou-se uma pesquisa de natureza qualitativa, onde, através da observação participante do investigador e com auxílio de um diário de campo, foi possível avaliar e melhorar a implementação de novas metodologias ativas da Educação 4.0, comprovando os efeitos do novo formato de aplicação de aulas.

0 desenvolvimento científico nos cursos técnicos necessita cada vez mais caracterizar-se pela interação entre criticidade e capacidade de adequada incorporação de múltiplas abordagens, com pressupostos teóricos da Educação 4.0, e metodologias e paradigmas capazes de atender às diversas demandas impostas pela nova revolução industrial.

Por esta pesquisa estar limitada a uma amostra específica, os resultados não podem ser generalizados. Contudo, este trabalho deixa em aberto uma proposta para futuros estudos sobre a temática, seja através de outros grupos de estudantes, seja através de outras disciplinas ou das novas qualidades que o mercado precisará.

\section{REFERÊNCIAS}

Aires, R. W. A., Moreira, F. K., \& Freire, P. S. (2017). Indústria 4.0: Competências requeridas aos profissionais da quarta revolução industrial. In L. M. F. Pereira, L. Visintin \& M. S. Gomes (Eds.) CIKI VII Congresso Internacional de Conhecimento e Inovação. Departamento de Engenharia e Gestão do Conhecimento/ Universidade Federal de Santa Catarina.

Andrade, K. (2019) Guia Definitivo da educação 4.0: Uma rede de conexões interligando pessoas e saberes. Planeta Educação. http://www.plannetaeducacao. com.br/portal/arquivo/editor/file/ebook-educacao4.0-planneta.pdf

Centro Estadual de Educação Tecnológica Paula Souza (2009). Plano de Curso para Habilitação Profissional de Técnico em Mecatrônica Integrado ao Ensino Médio. Número de Plano: 089. Eixo Tecnológico: Controle e Processos Industriais. Governo Estado de São Paulo.

Coutinho, C. P. (2008). A influência das teorias cognitivas na investigação em Tecnologia Educativa. Pressupostos teóricos e metodológicos, expectativas e resultados. Revista Portuguesa de Educação, 21(1), 101-127. https://doi.org/10.21814/ rpe.13921

Ensslin, L., \& Vianna W. B. (2008, Março). O design na pesquisa qualiquantitativa em engenharia de produção - questões epistemológicas. Revista Produção Online, 8(1), 1-16. https://doi.org/10.14488/1676-1901.v8i1.28

Hatch, M. (2013) The Maker Movement Manifesto: Rules for Innovation. Editora Mcgraw-Hill Professi.

Kloc, A. E., Koscianki, A., \& Pilatti, L. A. (2009). Robótica: uma ferramenta pedagógica no campo da computação. In A. C. Francisco, G. Dos Santos Jr. \& N. A. M. Pinheiro (Eds), Anais do I Simpósio Nacional de Ensino de Ciência e Tecnologia (pp. 1394-1403). Universidade Tecnológica Federal do Paraná - UTFPR. 
Leontiev, A. N. (1978). Actividad, conciencia y personalidad. Editora Ciencias del Hombre.

Prause, M., \& Weigand, J. (2016). Industry 4.0 and Object-Oriented Development: Incremental and Architectural Change. Journal of Technology Management \& Innovation, 11(2), 104-110. https://doi.org/10.4067/ S0718-27242016000200010

Morán, J. (2015). Mudando a educação com metodologias ativas. Coleção Mídias Contemporâneas. Convergências Midiáticas, Educação e Cidadania: Aproximações jovens, 2(1) 15-33.

Piaget, J. (1996). A construção do real na criança. Ática.

Piva Jr., D., \& Cortelazo, A. L. (2019). Uso da metodologia Flipped Classroom para a melhoria do desempenho de estudantes na disciplina de fundamentos de TI. In S. P. Silva et al. (Org.) Metodologias Ativas: Relatos de Experiências do Centro Paula Souza. (Vol. 1, pp. 29-34). Edições Brasil.

Siemens, G. (2004). Conectivismo: Uma teoria de Aprendizagem para a Idade Digital. Competências profissionais (B. Leite, Trans.). In: Webcompetencias http://docplayer.com.br/53538608-Conectivismo-uma-teoria-da-aprendizagempara-a-era-digital.html

Silva, M. B., \& Andrade, H. de S. (2019). As metodologias ativas de aprendizagem e a formação de profissionais classe mundial. In S. P. Silva et al. (Org.) Metodologias Ativas: Relatos de Experiências do Centro Paula Souza (Vol. 1, pp. 9-14). Edições Brasil.

Thompson, J. B. (2011). A mídia e a modernidade: Uma teoria social da mídia. Editora Vozes.

Vygotsky, L. S. (1989). Pensamento e Linguagem. Martins Fontes.






\title{
Active methodologies in a professional technical school
}

\begin{abstract}
The fourth industrial revolution has grown exponentially and it is visualized through additive manufacturing (3D and 4D printings), big data, the Internet of Things (IoT), intelligent sensors, augmented reality, digitalization, artificial intelligence, advanced robotics, among other advances in the so-called Industry 4.0. Thus, this research aims to investigate how the methodology of Education 4.0 can support pedagogical strategies in a technical school, offering new teaching resources and practices to train professionals for this advent. A descriptive case study of a qualitative nature was carried out through the implementation of a methodology based on the foundations of Education 4.0, in a mechatronics class in a technical school, in the context of the subject of Robotics, and a field journal and participant observation were used to describe the effects of the new application format of the classes. This new methodology demonstrated that the participating student in these classes was able to understand, identify, hone and act within the fourth industrial revolution, obtaining the necessary skills that this market demands. Change appears to be unavoidable with the Industry 4.0, even within the educational environment, making Education 4.0 the watchword among educators who want to prepare effective professionals for the labor market.
\end{abstract}

Keywords: Robotics, Education 4.0, Industry 4.0, Active Methodologies. 


\section{Metodologías activas en la escuela técnica profesional}

\section{RESUMEN}

La cuarta revolución industrial ha crecido exponencialmente y se visualiza a través de la fabricación aditiva (impresión 3D y 4D), big data, la Internet de las cosas (loT), sensores inteligentes, realidad aumentada, digitalización, inteligencia artificial, robótica colaborativa, entre otros avances en la denominada Industria 4.0. Por lo tanto, el objetivo de este trabajo fue investigar cómo la metodología de Educación 4.0 puede apoyar estrategias pedagógicas en una escuela técnica, al ofrecer nuevos recursos de enseñanza y práctica para capacitar a profesionales para este advenimiento. Se realizó un estudio de caso descriptivo cualitativo, mediante la implementación de una metodología basada en los fundamentos de la Educación 4.0 en un curso de mecatrónica en una escuela técnica, a través de la disciplina de Robótica, recurriendo a la observación participante para describir los efectos del nuevo formato de aplicación de clases. La Educación 4.0, con sus metodologías activas, demostró que el estudiante que participó en estas clases fue capaz de comprender, identificar, mejorar y actuar dentro de la cuarta revolución industrial, obteniendo las habilidades necesarias que requiere este mercado. El cambio parece ser inevitable con la Industria 4.0, incluso en del entorno educativo, haciendo de la Educación 4.0 la consigna entre los educadores que desean preparar profesionales efectivos para el mercado laboral.

Palabras clave: Robótica, Educación 4.0, Industria 4.0, Metodologías activas. 